\title{
Message from the Editor
}

\section{Dear reader,}

It is time to reflect on the developments in technologies for people with disabilities, and also on our journal: Technology and Disability.

A news item in an American Newspaper ${ }^{1}$ (March 2009) about John Colianni, who retired at the age of 84 from his job as a school bus driver, immediately draws attention to aging, and illustrates what is now happening in an aging society. When John Colianni celebrated his 60th birthday, discussion had already started in the newspapers and amongst social researchers suggesting that we could have problems in the decades to come. Indeed, from the beginning of the 1980s, reports on this issue were telling us that unless steps were taken to address the problem, the care requirements of the elderly were going to spiral out of control. Before the 1980s, attention was mostly drawn to the more challenging situations of people with serious disabilities, such as the casualties of conflict and those with congenital malfunctions. With the inevitable effects of aging in mind, more attention was required for the large numbers of people who also needed support for their daily functioning due to lesser handicaps, but could potentially still maintain a large degree of independence if they had such support. Since 1980, several European and worldwide initiatives have been taken to respond to the issue of aging by looking at the technologies used by the elderly, and by persons with disabilities in general.

Actions and initiatives originated in the field, but were also initiated and supported by the European Union. It is worth remembering that the European Union has remained dedicated to the vision of inclusion for all in our European society. Some keywords and initiatives are:

The TIDE pilot phase, based on a study by the Research and Development market of technology for the disabled. $^{2}$

\footnotetext{
${ }^{1}$ Post Standard, Syracuse / USA, March 23, 2009, Sean Kirst.

${ }^{2} \mathrm{http}: / / \mathrm{www}$.tiresias.org/phoneability/bridging the gap/chapter 3_2.htm.
}

The COST-219 research coordination group which followed, involved in the initiation of TIDE and the eInclusion/e-Accessibility policy developments and supported by the European Commission.

The set-up of the EDeAN network and a network of National contact centers with a rotating secretariat. ${ }^{3}$

There are many other initiatives, such as the founding of the AAATE in 2002 in Portugal and the extension of the journal Technology and Disability - started in the United States, where inclusion, accessibility and design for all developed under the name of Universal Design - into Europe. A good number of specific projects have been funded concentrating on design for all and inclusion. A recent trend in Europe is to focus on procurement; the expenditure of public funds on products and standards for sustainability in the creation of new accessible environments. This has had its effects in America, and the European approach will have an impact as well no doubt.

We now live in the year 2010 and the wave of post WWII 'baby boomers' is reaching retirement. It is time to evaluate the effects of all the initiatives, projects, policies and work we have done and the money that has been spent to cope with the challenges of an aging society. Society is not only coping with aging, but with new challenges of migration and the problems which a developing society poses for children and young people with disabilities. Also, society is in crisis, and existing facilities, systems for service provision and achievements may have to fight to be allowed to continue. Our goal is to learn from this evaluation, further improve good practice as a result and formulate what has to be increased, or added to current ongoing programs.

We plan to have content ready at the end of this year for a special issue on this matter, to be published in 2011, with the working title "Effects of past measures

\footnotetext{
${ }^{3}$ The first three NCCs to have responsibility for the EDeAN Secretariat were: Danish Centre in Denmark (July 2002 to Dec. 2003), IRV in the Netherlands (January 2004 to December 2004), and ICSFORTH in Greece (January 2005 to December 2005). See also the EDeAN charter and white paper found at the EDeAN web-site www.EdeAN.org.
} 
and policies related to technology, for the inclusion of persons with disabilities into society" or "Technology and inclusion effects" for short. I am looking for material on this subject which can demonstrate concrete results, and also for review papers on special topics in this area, so please send me your very best ideas.
Looking forward to your response, and wishing you a creative and positive mind,

Thijs Soede

Editor-in-Chief 